\title{
In-season prediction of yield variability in an apple orchard
}

\author{
V. Liakos ${ }^{1,2}$, A. Tagarakis ${ }^{1}$, K. Aggelopoulou ${ }^{1}$, S. Fountas ${ }^{3}$, G.D. Nanos ${ }^{4}$ and T. Gemtos ${ }^{1}$ \\ ${ }^{1}$ University of Thessaly, Laboratory of Farm Mechanization, Volos, Greece \\ ${ }^{2}$ University of Georgia, Department of Crop and Soil Sciences, Tifton, Georgia, USA \\ ${ }^{3}$ Agricultural University of Athens, Laboratory of Agricultural Engineering, Athens, Greece \\ ${ }^{4}$ University of Thessaly, Laboratory of Horticulture, Volos, Greece
}

\section{Summary}

Prediction of the spatial variability of apple yield as early as possible in the season is very important for farm managers. Many researchers used colour images of the apple trees and algorithms in order to develop prediction models of apple yield. The objective of this research was to study the spatial variability in an apple orchard and to develop methods for predicting yield variability within the growing period and as early as possible to permit management decisions. A commercial point-and-shoot and a multi-spectral camera were utilised to obtain images of the apple trees during the flowering period under daylight in a cv. Fuji apple orchard in Greece. The images were taken in April 2010 and 2011. Fruit yield was recorded at harvest each year. Supervised classification was used to isolate and calculate the flowers' pixel density of the whole image. For both years of the study, the results showed that, with both cameras, the estimated distribution of the flowers was correlated with the final yield distribution; however, for the second year, the correlation was slightly lower, probably due to adverse climatic conditions during and after the pollination period, which resulted in low yield. Multi-spectral images gave the best results in both years $(r=0.859$ in 2010 and $r=0.827$ in 2011).

\section{Keywords}

apples, flower distribution, multi-spectral images, spectral analysis, yield variability

\section{Introduction}

Yield prediction is a topic which concerns many producers of agricultural products. Farmers would like to know how much yield they are about to expect, as early as possible. Yield variability forecast can help farmers in setting future prices and insurance premiums as well as in applying fertilizers (Liakos et al., 2013), irrigation (Liakos et al., 2015) and other inputs site-specifically (Zude-Sasse et al., 2016). Due to all these advantages, yield prediction is of high importance in farming. However, a correct yield prediction relies on the method used and the relation of the studied characteristics with yield. Martin et al. (2005) pointed out that finding plant or soil characteristics that would correlate or predict yield variability would be of great importance. Historical data proved not to be reliable for yield variability prediction in annual crops [Blackmore et al. (2003) for wheat and Fountas et al. (2004) for cotton] while Bramley and Hamilton (2005) have found that temporal variability of vines is stable. An al-

\section{Significance of this study}

What is already known on this subject?

- Co-authors of this manuscript uncovered in the past that apple yield is related positively with the number of flowers when trees are in full bloom stage. Furthermore, it is known that flowers can be counted manually or by analyzing tree images.

\section{What are the new findings?}

- This manuscript presents two new methods for more accurate recording (by analyzing tree images) of the flower variability than the method suggested in the past. Additionally, the adverse weather conditions during the fruit set period of the second year gave the chance (for the first time up until now) to study the impact of the environment on the accuracy of the yield prediction.

What is the expected impact on horticulture?

- Mapping of flower variability to predict yield is very important in horticulture. Accurate prediction of flower variability and consequently prediction of yield variability can help farmers applying inputs such as irrigation and fertilizers site-specifically as well as to set future prices and insurance premiums. Additionally, site-specific thinning and winter pruning based on flower variability can help in the elimination of the alternate bearing phenomenon.

ternative way is to find characteristics of the crop within the growing season that can safely predict yield variability and permit site-specific management. Tanaka et al. (2004) used a CCD camera to take pictures of whole trees individually. By using the NDVI values of the trunk, the leaves and the stems, they segmented them. Except from identification of green objects, NDVI was used to separate the dry soil from the wet soil, and the muddy water from the clear water (Oklahoma State University, 2013). The successful identification of nongreen objects by using NDVI was done because each object has different spectral signatures at different wavelengths.

In orchards, Bulanon et al. (2002) developed a fruit detection system for robotic harvest of cv. Fuji apples based on a model which used the red colour to segment the apples from the background of the images. Similar work was done by Wachs et al. (2010), who tried to detect green apples by using thermal infrared and colour images, while Zhou et al. (2012) analyzed images of 'Gala' apple trees by using an algorithm with colour difference red minus blue and green minus red to define the fruits on the trees. Five years later, 
Cheng et al. (2017) developed two artificial neural network models for early yield prediction of 'Gala' apple trees. These models were analysing RGB images of the trees to identify the fruit and the leaves. These two models were proved to predict yield accurately $\left(\mathrm{R}_{\text {average }}^{2}=0.82\right)$. Linker et al. (2012) developed a four-step algorithm to detect the fruits on apple trees. The first step of the algorithm was the detection of the pixels which may represent an apple. The second was the formation and the extension of the areas which may belong to apples. The third was the segmentation of these areas from the background. Finally those areas were compared with a model of an apple. For validation of the algorithm, they used one dataset with RGB images of the trees where apples could be counted. The algorithm could detect $85 \%$ of the apples visible in the RGB images. Chinchuluun and Lee (2006) used four ultrasonic sensors and two charge-coupled device (CCD) cameras in order to capture citrus fruit on the trees. By developing an algorithm to analyse the data, they were able to predict the yield. Stajnko and Cmelik (2005) tried to model the growing stages of the fruit in a 4-year-old apple orchard. They used RGB images of the fruit and concluded that the number of fruit identified in the images correlated with final yield. Similar studies were done by Safren et al. (2007), who used multi-spectral images of the apple trees. Annamalai and Lee (2003) created an algorithm for image analysis to estimate citrus distribution in an orchard. The main aim of the work was to count the citrus fruit captured by a digital image. After analyzing 59 images, they concluded that the correlation coefficient between the counted fruits from the images and those harvested was 0.76 . Despite the fact that research on image analysis of fruits, at different stages during fruit growth, to predict yield gave good results, the procedure was time-consuming and was applied too late in the growing period to permit site-specific management.

Prediction of apple yield by using the number of the flowers on the trees was carried out with good results by Aggelopoulou et al. (2010, 2011). Aggelopoulou et al. (2010) measured manually the flower buds, following the stereology methodology, in an apple orchard and they found high correlation between the flower spatial distribution and final yield ( $\mathrm{r}=0.78$ ). Additionally, Aggelopoulou et al. (2011) photographed 250 trees with a commercial digital camera and after analysing 113 photos of them, they found high correlation between the number of flowers and the yield. Koutsostathis et al. (2009) used a digital camera to take images during flowering. The results of image processing showed a good correlation between the number of pixels which represent flowers in the images and yield. This method provided good yield prediction early in the growing season. The model predicted yield variability from the estimated number of flowers with an error of about 13-14\%. Yield variability prediction was quite accurate even though after flowering, uniform hand thinning of the fruits and fruit drop affect the final fruit number. According to Lakso and Robinson (1997), who performed thinning trials on apple trees, fruit thinning is used in apple orchards to improve the fruit size while yield is closely related to flower density assuming adequate pollination. Moreover, fruit drop did not affect significantly the fruit yield. It should be noted that apple tree architecture helped the experiments of Aggelopoulou et al. (2001) and Koutsostathis et al. (2009), as apple trees had small size, no continuous growth, and monopodial branching pattern. In palmette-shaped apple orchards the task is even easier as the trees form a two-dimensional wall, making flowers' images more clear.
Yield variability prediction by flower variability mapping has the advantage of early in the season warning and offers the opportunity to use this information to improve management of the orchard. The aim of this study was to improve the accuracy of early yield prediction by using image processing techniques for flower counting. Therefore, a "point-and-shot" and a multispectral camera were utilized to capture images of the apple trees during the full bloom stage. The specific objectives of the present paper were: (1) to describe the image capturing techniques and the image analysis process; for flower counting in apple orchards; (2) to evaluate the results of the image process by analysing the relation between the estimated percent of pixels representing flowers and the final yield; and (3) to compare the estimated flower distribution maps with the real yield variability maps.

\section{Materials and methods}

\section{Site description}

The experiment was carried out on a 6-years-old 1 ha commercial apple orchard located at Aetolofos area of Central Greece $\left(39^{\circ} 39^{\prime} 53.20^{\prime \prime} \mathrm{N}, 22^{\circ} 44^{\prime} 14.28^{\prime \prime} \mathrm{E}\right)$. To the north and west of the orchard, there were other apple orchards, to the south there was natural vegetation (shrubs) and to the east there was a wheat field. The orchard was planted with two apple cultivars. The main cultivar was cv. Fuji and cv. Red Chief used as a pollinator ( 5 rows of 'Fuji' and 1 row of 'Red Chief'). Tree rows were spaced $3 \mathrm{~m}$ apart and trees in the row were $0.6 \mathrm{~m}$ apart. Trees were trained as free palmette and fruit hand thinning was performed uniformly, with low intensity, about one month after full bloom.

One common significant economic problem in orchards with cv. Fuji as main cultivar is the alternate bearing. During an "on-crop" year, apple trees produce many small fruit while during an "off-crop" year, trees produce less apples (Schupp, 2011).

\section{Data collection}

The research was conducted in 2010 and 2011. Year 2010 was a normal year without disease and pest problems and optimal weather during fruit set. In 2011, there were no pest and disease problems but the weather during the fruit set was not optimal because of high air humidity, low temperatures and high precipitation. Images of flower density were collected during April 2010 and 2011 when the trees were at the full bloom stage. This stage is defined as the day that at least $60 \%$ of the king blossoms are opened. King blossoms are the large blossoms which are located at the centre of the blossom cluster. In both years, when the apple trees were at this stage, the flowers had white colour, the branches were brown while there was a small amount of small green leaves. This helps the image analysis as the colours of the objects are completely different and it is easy to discriminate them. In the current research the photos were taken every fifth tree along the row ( $3 \mathrm{~m}$ ) and every other row (6 m). Two devices were used simultaneously.

A multi-spectral camera (custom model, Quest Innovations, The Netherlands) equipped with filters, recorded the images in three channels; visible wavelengths (red: $630-680 \mathrm{~nm})$, near infrared $(690-830 \mathrm{~nm})$, near infrared $(830-1,000 \mathrm{~nm})$. A laptop was used to store the photographs as the multi-spectral camera did not have internal memory. The connection between the multi-spectral camera and the laptop was established by using a PCI card and commercial software (FrameLink Express, Imperx, USA). The selected 


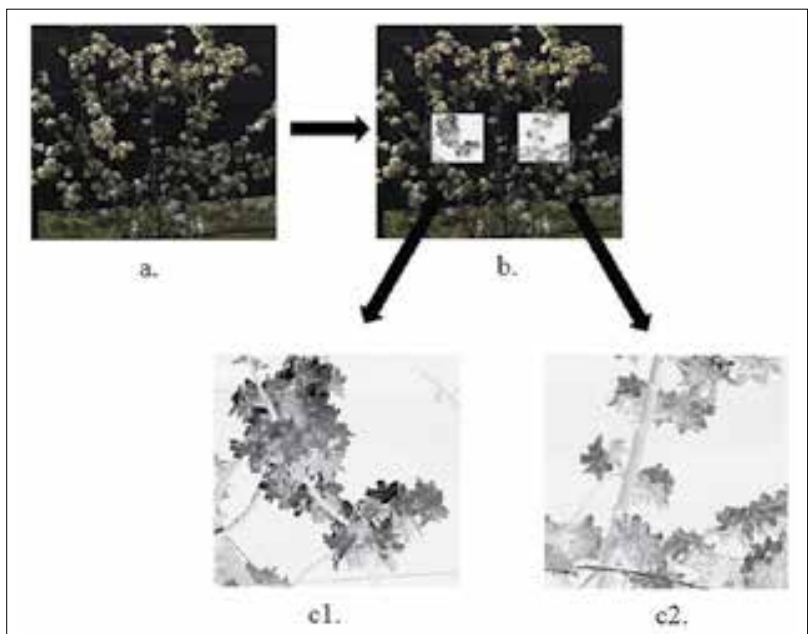

FIGURE 1. a) before the image analysis; b) after performing the described procedure of image analysis, c1) and c2) the results of the image analysis.

trees were photographed at two places at the left and right of the trunk at a height of $1.2 \mathrm{~m}$ from the ground. The captured area in each image was $300 \mathrm{~mm} \times 300 \mathrm{~mm}$ which means that $3,600 \mathrm{~cm}^{2}$ of the tree canopy was analyzed. Tree canopies were photographed in this way because of the lack of a zoom option in the multi-spectral camera.

The second camera (Olympus E-420, USA) was a commercial point-and-shoot digital camera and had 10 megapixels resolution. The same trees were photographed by both cameras, but the point-and-shoot digital camera imaged the whole tree. In both cases, it was not applied any type of image correction and a piece of black fabric was held behind the tree as background (Figure 1a).

In mid-October 2010 and in early November 2011, the apples were hand harvested. The apples were placed into plastic crates, with a capacity of $20 \mathrm{~kg}$, left along the tree rows before being loaded on to a platform. The workers were completely filling the crates as they moved along the tree rows. It was impossible to separate the yield from each tree due to the palmette formation. Before harvest, each row was divided into $10 \mathrm{~m}$ sections. All crates from each group of $10 \mathrm{~m}$ sections were collected together and weighed to give the yield of $10 \mathrm{~m}$ of row in order to create a yield map. This length was selected to minimize the error, due to the way the crates were filled. The geographical position of the middle tree of each part was recorded using a GPS device (Etrex Legend $\mathrm{H}$, Garmin, USA). The number of the flowers estimated by each of the two methods described earlier was then correlated with total yield.

\section{Image analysis}

1. Interpretation of images captured with the point-andshoot camera. One image per tree was taken each year, with the point-and-shoot camera (370 images per year). For the image analysis, the GIMP 2.6.8 (GNU, USA) software was utilized. At the beginning of the analysis, 20 photos were selected randomly for analysis because the range of the pixel values representing the flowers was unknown. The analysis of the images concentrated on the canopy area of the trees (300 $\mathrm{mm} \times 300 \mathrm{~mm}$ at $1.2 \mathrm{~m}$ height, left and right of the trunk, the average of the number of pixels representing flower were calculated). Initially, the areas that should be analysed were defined. Then, the colours of the images were con- verted into gray scale using the desaturation procedure (Figure $1 \mathrm{~b})$. The gray level was calculated by using the function:

$$
x=0.21 * R+0.72 * G+0.07 * B
$$

where: $x$ is the new pixel value at the gray scale, $R, G, B$ are the pixel values at the Red, Green and Blue area of the electromagnetic spectrum.

This step helped to isolate the flowers (white colour) from the other objects in the images (stems etc.). The pixel values ranged from 0 (black) to 255 (white). Then, the invert value filter was used to invert all the pixel colours and brightness values as if the images were converted into negative (Figure 1c). It was identified that the range of the pixel values representing the flowers was from zero to one hundred. 2. Interpretation of multi-spectral images. The number of multi-spectral images captured was 740 in each year (two images per tree, at the left and right of the trunk at a height of $1.2 \mathrm{~m}$ from the ground). Because of the large number of images, the two images of each tree were grouped together using the mosaicking procedure with the ERDAS software (Erdas Inc., USA). This analysis was carried out in the same trees as used for the analysis of the images captured by the point and shoot camera.

In the present research, the ENVI 4.7 (Research Systems, USA) software was used to transform the original images into images containing the NDVI values of the objects, as this software can perform spectral and terrain analysis. It should be mentioned that the NDVI function was used to transform the original images into NDVI images. Initially, because the NDVI values of the pixels representing the flowers were unknown, 20 randomly selected images were analysed. After the appliance of supervised classification by utilizing the ERDAS Imagine 8.5 software and by knowing the flowers areas, it was found that the range of the pixel values representing the flowers was always between 0 and 0.007 (Figure 2). Subsequently, all multi-spectral images were transformed to NDVI images by using the procedure mentioned above. The

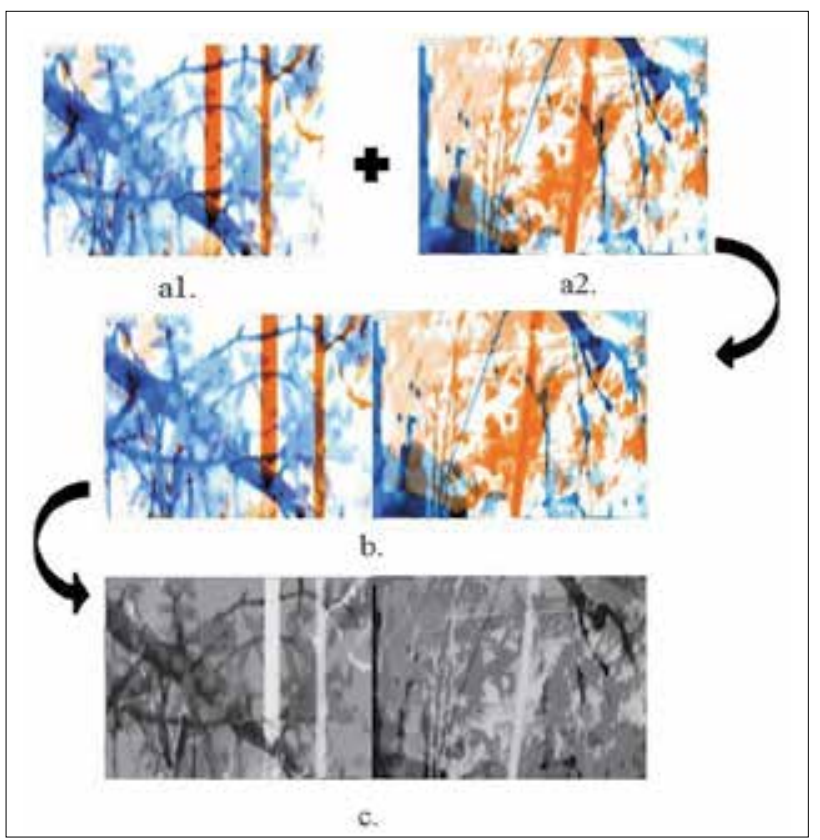

FIGURE 2. a1) and a2) images as captured from multispectral camera, b) two images attached together, c) final image containing the NDVI values. 
percent of the pixel with NDVI values from 0 to 0.007 representing the flowers was calculated.

\section{Data analysis}

In the current research for the comparison of yield and flower data, a grid $10 \mathrm{~m} \times 12 \mathrm{~m}$ was selected that fits to $10 \mathrm{~m}$ along the row yield measurement and four rows of trees (double to yield measurement density). Additionally for every $12 \mathrm{~m}$ of apple trees, there was one row with pollinator trees. Consequently, all measured data were transformed into $10 \mathrm{~m} \times 12 \mathrm{~m}$ grid by calculating the mean value in each grid cell by utilizing the ArcGis 9.3 (ESRI, USA) software. Initially, the grid layer was formed into 56 polygons. Continuously, the layers with the flower and yield data (points) were joined to the grid layer using the mean function to calculate the mean values of the points included in each grid cell. Moreover, in the generated maps of yield and flowers, four classes were used to represent the data. The classification method used was the quantile by which each class had the same number of features. To compare the final yield maps with flower maps, each polygon took a number from one to four according to the class in which it existed. Finally, the number of matched polygons between yield and flowers was calculated.

The software SPSS 16.0 Winwrap Basic (IBM Corporation, New York) was used for statistical analysis of the data. Specifically, the descriptive statistics were exported while Pearson's correlation was calculated to find the correlation between yield and flower data. Additionally, Microsoft Excel 2007 software was utilized to create scatter plots of the photos and yield data.

\section{Weather data}

Weather during pollination affects directly pollination of the ovary through pollen tube growth, difficulty of pollen movement and through the reduced bees' movement.

In order to assess the weather effect to pollination daily relative humidity ( $\mathrm{RH}$ ) and the temperature (T), for both years, were acquired from the National Meteorological Service of Greece (EMY). The daily precipitation data were downloaded from a weather station near by the orchard. The mean values of $\mathrm{RH}, \mathrm{T}$ and precipitation every 5 days in the interval from the $1^{\text {st }}$ of April until mid-May (the fruit set period) of both years were calculated.

\section{Results and discussion}

The results of the two years obtained from the digital images analysis were compared with yield (Figures 3-6). Figures 3 and 4 are scatter plots which represent the percentage of flowers in the picture from the point-and-shoot camera in relation to the total yield of the same sampling location in 2010 and 2011. The Pearson correlation coefficient (r) was 0.855 and 0.816 , respectively, which are statistically significant at $\mathrm{p}<0.01$.

Figures 5 and 6 are the scatter plots which represent the percentage of flowers in the images from the multi-spectral camera in relation to the total yield in 2010 and 2011. The Pearson correlation between flowers and final yield gave $r=$ 0.859 in 2010 and $r=0.827$ in 2011 respectively, which are statistically significant at $\mathrm{p}<0.01$.

In 2010, it was clear that the relationship between percent of flowers and apple yield data were less scattered with both imaging methods (Figures 3 and 5) due to higher yield than in 2011. On the other hand, in 2011, the distribution of the points (Figures 4 and 6) was wider than in 2010 and the correlation coefficients between the number of flowers and the yield were slightly lower. This may have resulted from insufficient pollination and low fruit set. In 2010, relative humidity (it was 64.5\%: average in the first two weeks of April) decreased gradually during the pollination and fruit set period (21 $1^{\text {st }}$ April $-15^{\text {th }}$ May 2010) by approximately $10 \%$ giving better conditions for pollination and bees movement. Air temperature (it $16.2^{\circ} \mathrm{C}$ : average during the pollination period) was acceptable for insect mobility. In 2011, relative humidity (75\%: average of the period $1^{\text {st }}$ April - mid-May) remained high throughout the crucial pollination period while precipitation $(0.77 \mathrm{~mm}$ : average) was high and air temperature was relatively low $\left(13.7^{\circ} \mathrm{C}\right.$ : average). When relative humidity and precipitation are high and air temperature is close to or below $15^{\circ} \mathrm{C}$ during the pollination period, the pollen-dispersing insects (mainly bees in apple orchards) fly less and only close to their beehives resulting in poor pollen dispersal. The high relative humidity in combination with cloudy conditions and low air temperatures during April and early May 2011 should have delayed pollen tube growth resulting in unsuccessful ovary fertilization and reduced fruit set as is commonly found in apples under similar adverse weather conditions (Childers et al., 1995).

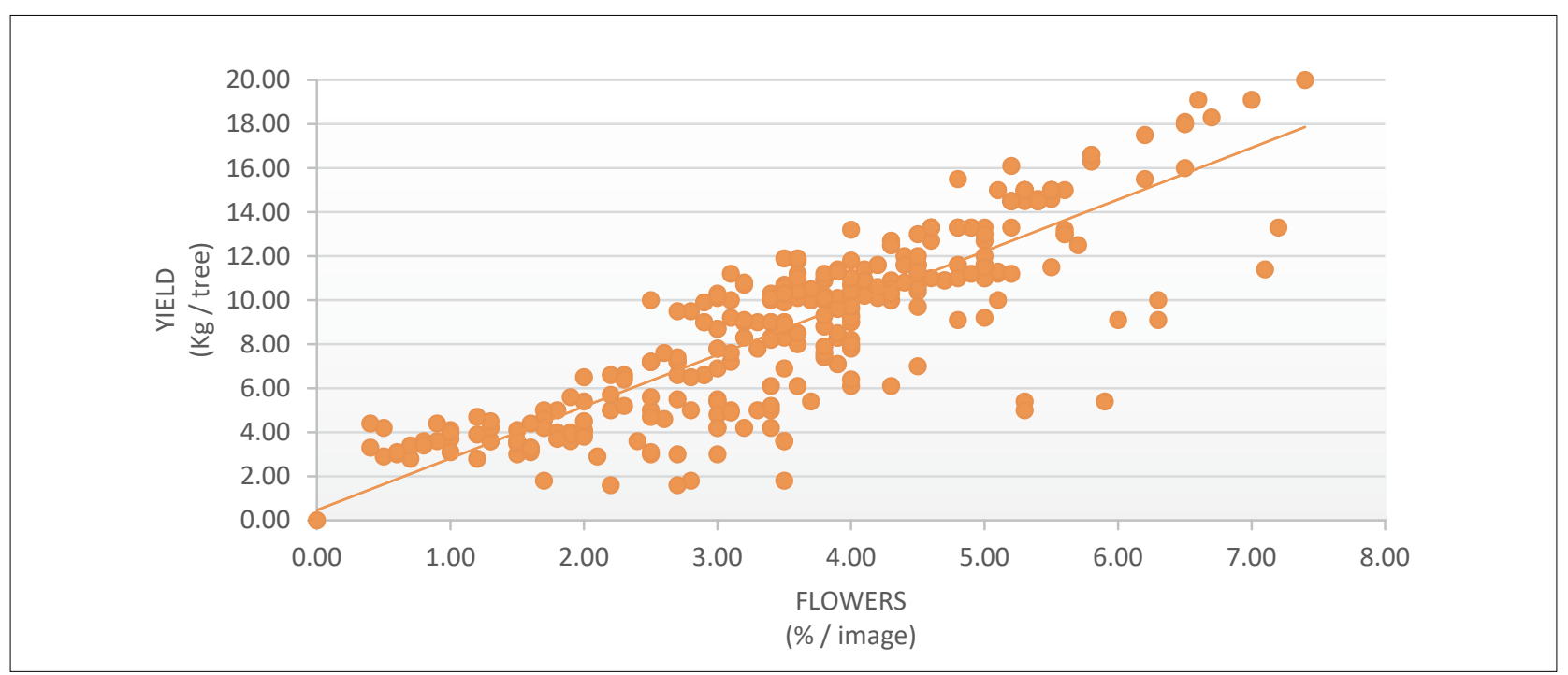

FIGURE 3. Scatter plot of the yield and flower data of 2010 using point-and-shoot camera. 


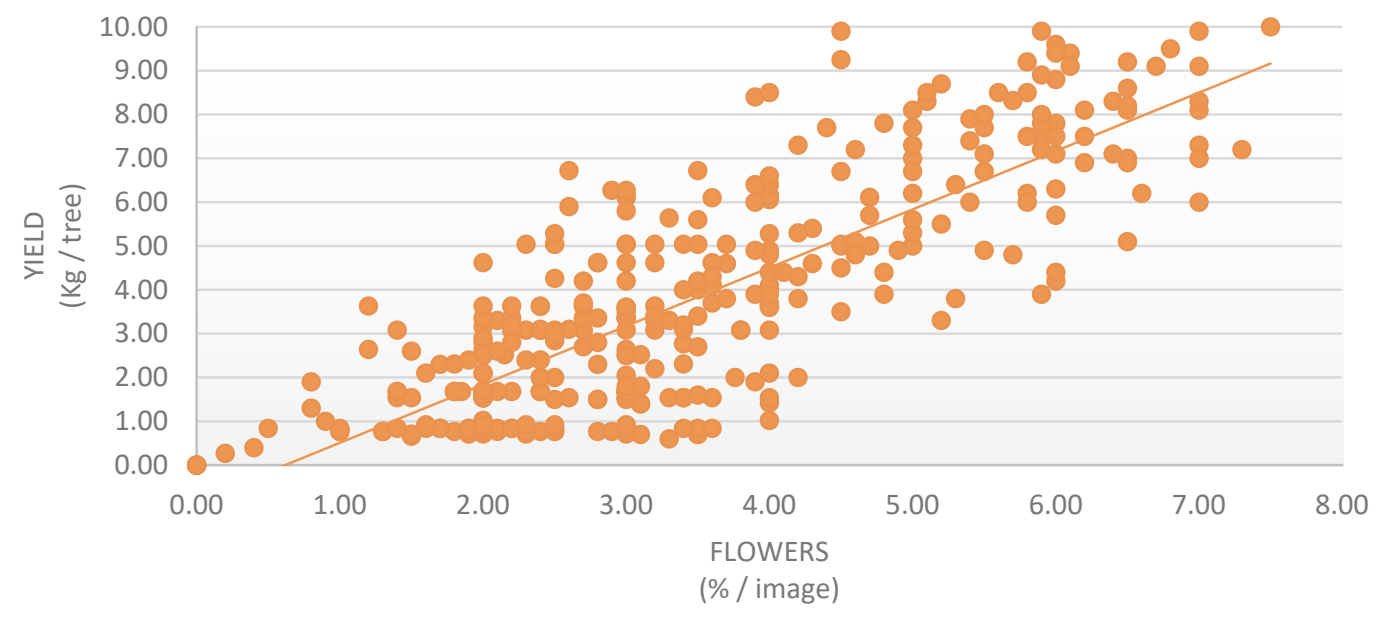

FIGURE 4. Scatter plot of yield and flower data of 2011 using point-and-shoot camera.

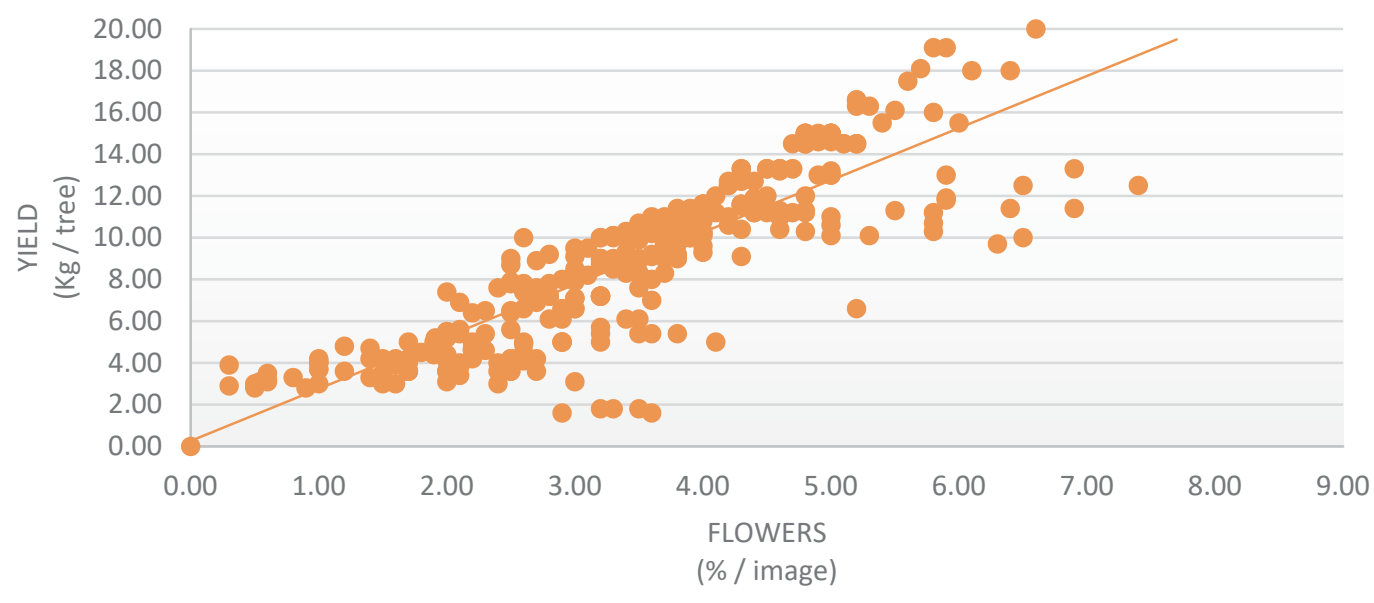

FIGURE 5. Scatter plots of yield and flower data of 2010 using multispectral camera.

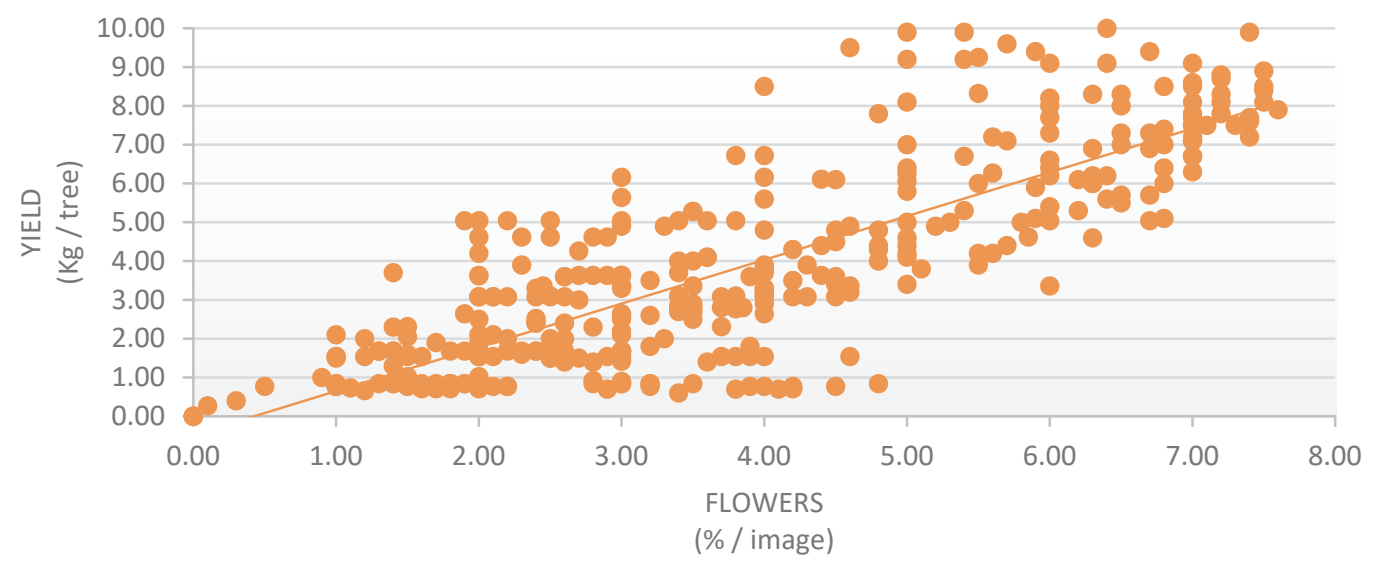

FIGURE 6. Scatter plots of yield and flower data of 2011 using multispectral camera. 


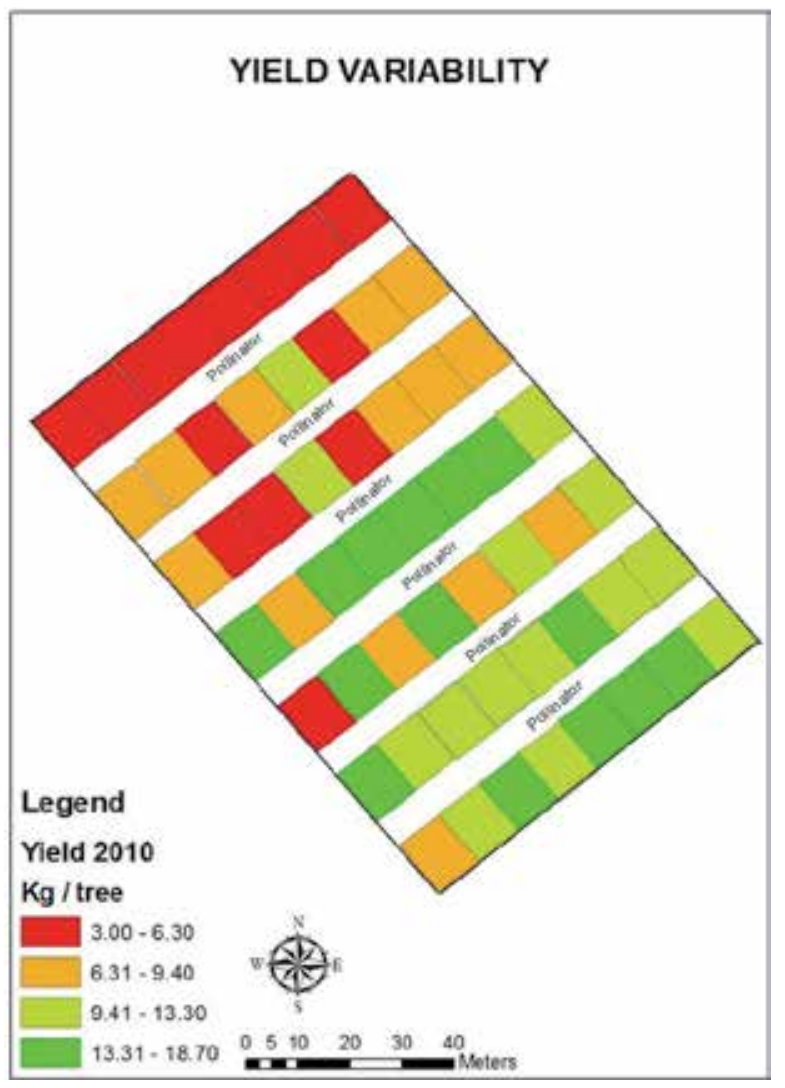

FIGURE 7. Yield in 2010.

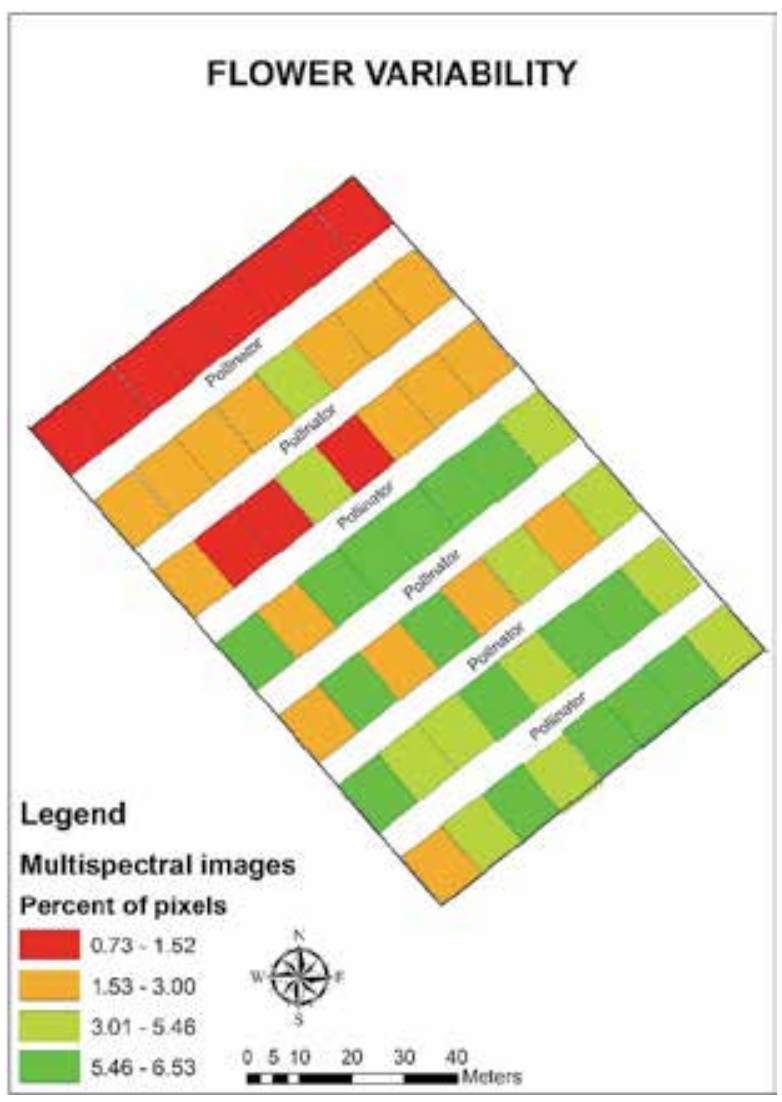

FIGURE 9. Flower density map obtained from multispectral images.

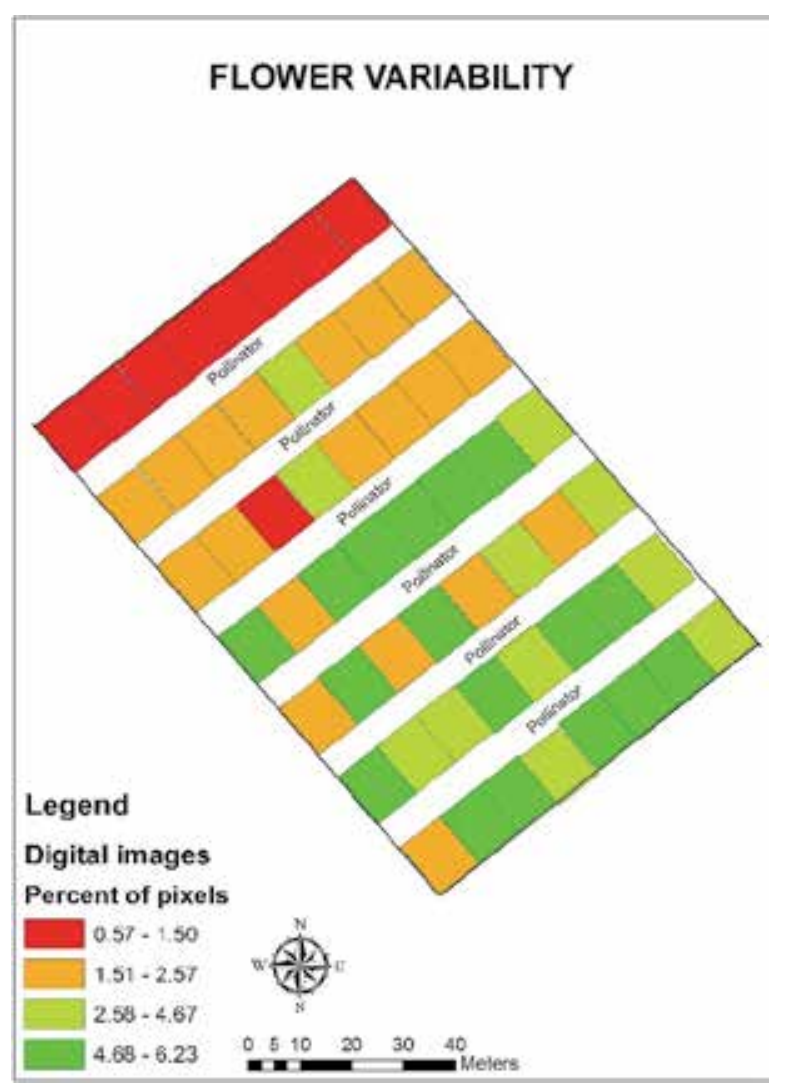

FIGURE 8. Flower density obtained from RGB images.

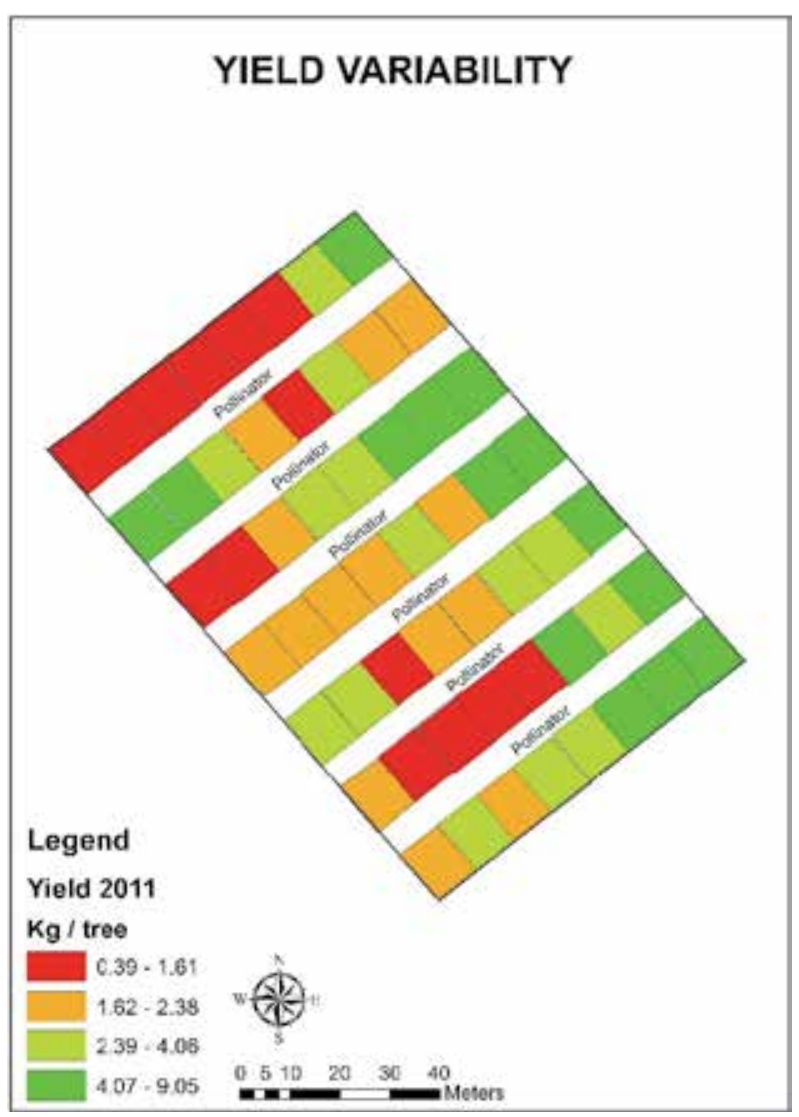

FIGURE 10. Yield in 2011. 


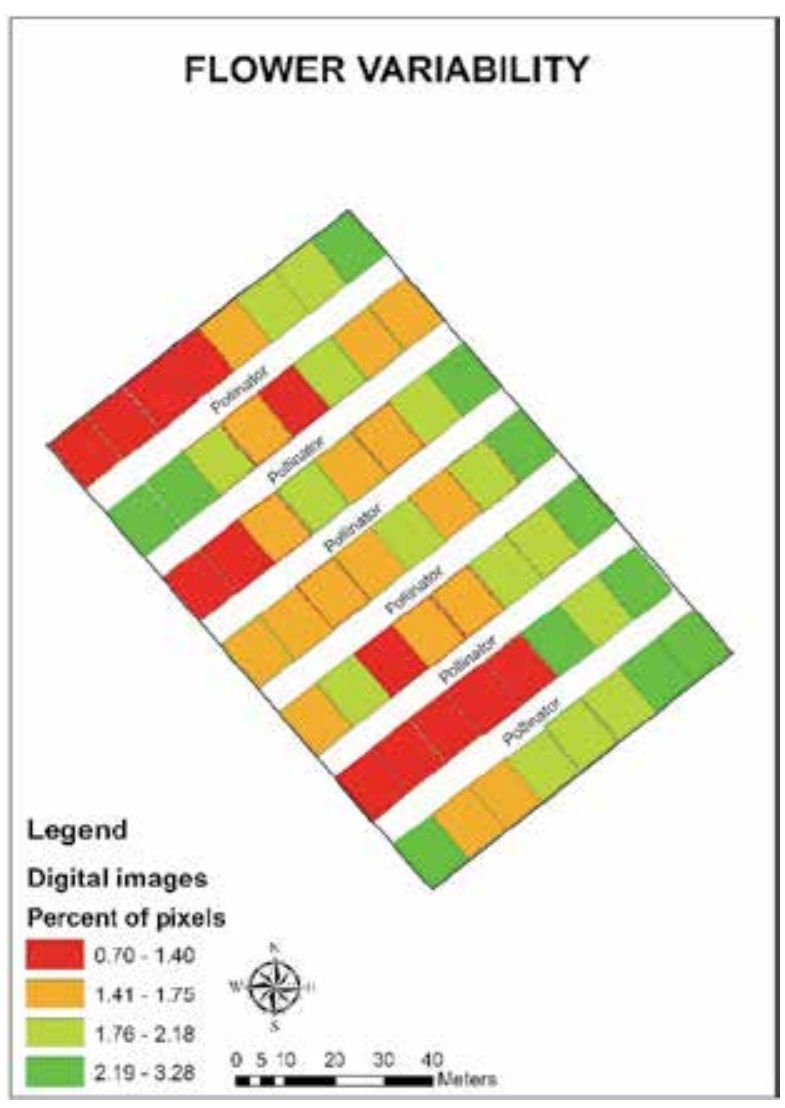

FIGURE 11. Flower density map obtained from RGB images.

Figure 7 shows the yield map of 2010. In the northern part of the orchard, the yield was low and, in the southern part, was high. Figure 8 shows the flower variability as obtained from the images captured with the point-and-shoot camera and Figure 9 the multi-spectral images for 2010. These two figures are similar and they clearly display similar variability with the yield map. This was expected as higher correlation between the number of flowers and total yield was found in 2010. The comparison of the flower variability map obtained from the multi-spectral camera NDVI images, with the yield map showed that 51 polygons out of 56 were in the same class while with the point-and-shoot camera, 48 out of the total 56 polygons.

The overall yield was much lower in 2011 than in 2010 probably due to adverse weather conditions as described above, and to lesser extent, due to alternate bearing (lower flower density in 2011). In 2011, there were five locations in the orchard where the yield was low and only at the eastern part of the orchard the yield was high. The map with the flower variability obtained from multi-spectral camera had 46 polygons in the same class (same colour) as the yield map. Additionally, 45 polygons were in the same class (same colour) in the yield and flower variability maps as obtained from the use of point-and-shoot camera.

From the above results, it can be concluded that there was a significant correlation between yield and flower variability. Similar correlations, as obtained from the first year of this research, were presented by Aggelopoulou et al. (2010) with $r=0.78$ when they measured the flowers buds of the apple trees manually and Aggelopoulou et al. (2011) with $r=$

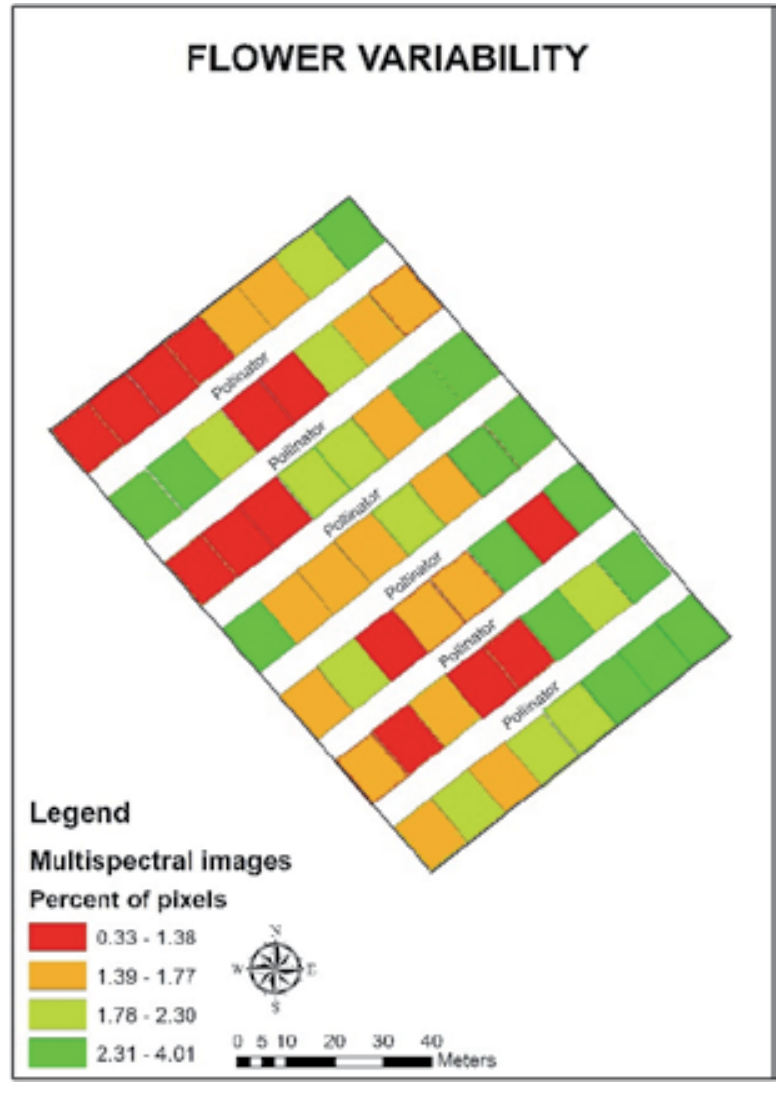

FIGURE 12. Flower density map obtained from multispectral images.

0.85 when they utilised only a commercial RGB camera to measure the flowers from the apple trees.

The use of NDVI worked well to discriminate the flowers from the other objects of the multispectral images. The estimation of the flowers early in the growing season could be a very important tool for the farmers and the industry as a prediction of yield variability in an orchard and a given year. Knowing approximately, from the flower variability, the yield in each orchard, farmers can manipulate production costs by using the prunings and the previous years yield data in order to estimate the removal of nutrients and to adjust the inputs. Furthermore, farmers and industry can manage their enterprises more efficiently as marketing plans can be fine-tuned based on the expected yield. From productivity point of view, the prediction of yield early in the season by using image analysis and flower variability can be benefecial for farmers since they have the advantage of applying thinning and pruning site specifically and not uniformly as they currently do. Additionally, site-specific thinning and winter pruning based on flower variability and consequently yield variability can help in the elimination of the alternate bearing phenomenon if they will be applied judiciously (Schupp, 2011).

Finally, both methods used in the current research gave similar results but the better method was using the multi-spectral camera. However, the recommended method for production use is the point-and-shoot camera because of its low cost compared to a multi-spectral camera, and the use of free image processing software for the analysis, as in our case. 


\section{Conclusions}

From the present research, it was concluded that:

a) The flower variability of the trees was positively correlated with the variability of final yield.

b) The flower estimation method using the multi-spectral camera gave similar estimation of the variation of total yield to the point-and-shoot digital camera. The difference was not so large and given the cost difference, it seems that point-and-shoot cameras can offer satisfactory results.

c) The two methods studied can be used to measure flower density in the canopy and thus predict the yield variability early in the growing season.

d) The number of flowers explained a large part of yield variability. However, the weather conditions should also be taken into consideration as they affect final yield. Based on the weather during flowering and fruit set, higher or lower correlations with final yield would be expected.

\section{References}

Adamsen, F.J., Coffelt, T.A., Nelson, J.M., Barnes, E.M., and Rice, R.C. (2000). Method for using images from a colour digital camera to estimate flower number. Crop Sci. 40(3), 704-709. https://doi. org/10.2135/cropsci2000.403704x.

Aggelopoulou, K., Wulfsohn, D., Fountas, S., Gemtos, T., Nanos, G., and Blackmore, S. (2010). Spatial variation in yield and quality in a small apple orchard. Prec. Agric. 11(5), 538-556. https://doi. org/10.1007/s11119-009-9146-9.

Aggelopoulou, K., Bochtis, D., Fountas, S., Swain, K., Gemtos, T., and Nanos, G. (2011). Yield prediction in apple orchards based on image processing. Prec. Agric. 12(3), 448-456. https://doi.org/10.1007/ s11119-010-9187-0

Annamalai, P., and Lee, W.S. (2003). Citrus yield mapping system using machine vision. ASAE Paper No 031002 (St. Joseph, Michigan, USA). https://doi.org/10.13031/2013.13701.

Arno, J., Bordes, X., Ribes-Dasi, M., Blanco, R., Rosell, R., and Esteve, J. (2005). Obtaining grape yield maps and analysis of within field variability in Raimat (Spain). In Precision Agriculture, Proceedings of the $5^{\text {th }}$ European Conference on Precision, J.V. Stafford, ed. (Wageningen, The Netherlands: Wageningen Academic Publishers), p. 899-906. https://doi.org/10.3920/978-90-8686-549-9.

Bramley, R.G.V., Proffitt, A.P.B., Hinze, C.J., Pearse, B., and Hamilton, R.P. (2005). Generating benefits from Precision Viticulture through selective harvesting. In Precision Agriculture, Proceedings of the $5^{\text {th }}$ European Conference on Precision Agriculture, J.V. Stafford, ed. (Wageningen, The Netherlands: Wageningen Academic Publishers), p. 891-898. https://doi.org/10.3920/978-90-8686-549-9.

Bulanon, D.M., Kataoka, T., Ota, Y., and Hiroma, T. (2002). A segmentation algorithm for the automatic recognition of 'Fuji' apples. Biosyst. Engin. 83, 405-412. https://doi.org/10.1006/bioe. 2002.0132.

Cheng, H., Damerow, L., Sun, Y., and Blanke, M. (2017). Early yield prediction using image analysis of apple fruit and tree canopy features with neural networks. J. Imaging 3(1), 6. https://doi. org/10.3390/jimaging3010006.

Childers, N.F., Morris, J.R., and Sibbett, G.S. (1995). Modern Fruit Science (Gainesville, Florida: Horticultural Publications), Ch. VI.

Chinchuluun, R., and Lee, W.S. (2006). Citrus yield mapping system in natural outdoor scenes using the watershed transform. ASABE Paper No. 063010 (St. Joseph, Michigan, USA).

Durrence, J., Hamrita, T., and Vellidis, G. (1999). A load cell based yield monitor for peanut feasibility study. Prec. Agric. 1(3), 301-317. https://doi.org/10.1023/A:1009925125359.
Gemtos, T.A., Markinos, A., and Nassiou, T. (2005). Cotton lint quality spatial variability and correlation with soil properties and yield. In Precision Agriculture, Proceedings of the $5^{\text {th }}$ European Conference on Precision Agriculture, J.V. Stafford, ed. (Wageningen, The Netherlands: Wageningen Academic Publishers), p. 361-368. https://doi.org/10.3920/978-90-8686-549-9.

Hofman, A.R., Penigrahi, S., Gregor, B., and Walker, J. (1995). In field monitoring sugar beets. ASABE Paper No. 95-2114 (St. Joseph, Michigan, USA). https://doi.org/10.4271/952114.

IBM Corporation (2007). SPSS 16.0. Winwrap Basic (New York: Polar Engineering and Consulting)

Koutsostathis, A., Bohtis, D., Aggelopoulou, A., Fountas, S., and Gemtos, T. (2009). Foreseen and spatial variability of production in apple orchard by estimating the number of flowers via treatment of digital pictures. In Proceedings of the $6^{\text {th }}$ Greek Conference of Agricultural Machinery (Thessaloniki, Greece: E.G.M.E.), p. 601-608.

Liakos, V., Tagarakis, A., Vatsanidou, A., Fountas, S., Nanos, G., and Gemtos, T. (2013). Application of variable rate fertilizer in a commercial apple orchard. In Precision Agriculture, Proceedings of the $9^{\text {th }}$ European Conference on Precision Agriculture, J.V. Stafford, ed. (Wageningen, The Netherlands: Wageningen Academic Publishers), p. 675-681. http://dx.doi.org/10.3920/978-90-8686-778-3_83.

Liakos, V., Vellidis, G., Tucker, M., and Liang, Xi (2015). A decision support tool for managing precision irrigation with center pivots. In Precision Agriculture, Proceedings of the $10^{\text {th }}$ European Conference on Precision Agriculture, J.V. Stafford, ed. (Wageningen, The Netherlands: Wageningen Academic Publishers), p. 677-684. https://doi.org/10.3920/978-90-8686-814-8_84.

Linker, R., Cohen, O., and Naor, A. (2012). Determination of the number of green apples in RGB images recorded in orchards. Comp. and Electr. 81, 45-57. https://doi.org/10.1016/j.compag.2011.11.007.

Marino, B., Geissler, P., O'Connel, B., Dieter, N., Burgess, T., Roberts, C., and Lunine, J. (1999). Multispectral imaging of vegetation at Biosphere 2. Ecol. Engin. 13(1-4), 321-331. https://doi. org/10.1016/S0925-8574(98)00108-6.

Martin, F.N., Bollero, G., and Bullock, D. (2005). Association between field characteristics and soybean plant performance using canonical correlation analysis. Plant and Soil 273(1-2), 39-55. https://doi. org/10.1007/s11104-004-6639-1

Miller, W.M., and Whitney, J.D. (1999). Evaluation of weighing systems for citrus yield monitoring. Appl. Engin. in Agric. 15(6), 609-614. https://doi.org/10.13031/2013.5825.

Pan, G., Li, F., and Sun, G.J. (2007). Digital camera based measurement of crop cover for wheat yield prediction. In Geoscience and Remote Sensing Symposium. IEEE International, 23-28 July 2007, p. 797800. https://doi.org/10.1109/IGARSS.2007.4422917.

Safren, O., Alchanatis, V., Ostrovsky, V., and Levi, O. (2007). Detection of green apples in hyperspectral images of apple-tree foliage using machine vision. Transactions of the ASABE 50(6), 2303-2313. https://doi.org/10.13031/2013.24083.

Schupp, J. (2011). Alternate bearing in fruit crops. Penn State Extension. Online: http://extension.psu.edu/plants/tree-fruit/news/ 2011/alternate-bearing-in-fruit-crops (Accessed 01.04.2017).

Stajnko, D., and Cmelik, Z. (2005). Modeling of apple fruit growth by application of image analysis. Agric. Conspectus Scientificus 70(2), 59-64. http://hrcak.srce.hr/909.

Swain, K.C., Zaman, Q.U., Jayasuriya, H.P.W., and Zhang, F. (2008). Estimation of rice yield and protein content using remote sensing image acquired by radio controlled unmanned helicopter. ASABE Paper No. 080038 (St Joseph, Michigan, USA). https://doi.org/ $10.13031 / 2013.24673$ 
Tanaka, T., Park, H., and Hattori, S. (2004). Measurement of forest canopy structure by a laser plane range-finding method improvement of radiative resolution and examples of its application. Agric. and Forest Meteor. 125, 129-142. https://doi.org/10.1016/j. agrformet.2004.02.008.

Taylor, J.A. (2004). Digital terroirs and precision viticulture: Investigations into the application of information technology in Australian vineyards. (M.Sc. Thesis) (Sydney, Australia: Australian Centre for Precision Agriculture, Faculty of Agriculture, Food and Natural Resources, University of Sydney).

Vellidis, G., Perry, C., Rains, G., Thomas, D., Wells, N., and Kvien, C. (2003). Simultaneous assessment of cotton yield monitors. ASABE 19(3), 259-272. https://doi.org/10.13031/2013.13658.

Wachs, J.P., Sturm, H.J., Burks, F., and Alchanatis, V. (2010). Low and high-level visual feature-based apple detection from multi-modal images. Prec. Agric. 11(6), 717-735. https://doi.org/10.1007/ s11119-010-9198-x.

Whitney, J.D., Ling, Q., Miller, W.M., and Wheaton, T.A. (2001). A DGPS yield monitoring system for Florida citrus. Appl. Engin. in Agric. 17(2), 115-119. https://doi.org/10.13031/2013.5451.

Zaman, Q.U., Schumann, A.W., Percival, D.C., and Gordon, J. (2008). Estimation of wild blueberry fruit yield using digital colour photography. Transactions of the ASABE 51(5), 1539-1544. https:// doi.org/10.17660/ActaHortic.2009.824.6.

Zhou, R., Damerow, L., Sun, Y., and Blanke, M. (2012). Using colour features of cv. 'Gala' apple fruits in an orchard in image processing to predict yield. Prec. Agric. 13(5), 568-580. https://doi.org/10.1007/ s11119-012-9269-2.

Zude-Sasse, M., Fountas, S., Gemtos, T.A., and Abu-Khalaf, N. (2016). Applications of precision agriculture in horticultural crops. Eur. J. Hortic. Sci. 81, 78-90. https://doi.org/10.17660/eJHS.2016/81.2.2.

Received: Jan. 27, 2017

Accepted: May 16, 2017

Addresses of authors:

V. Liakos ${ }^{1,2, *}$, A. Tagarakis ${ }^{1}$, K. Aggelopoulou ${ }^{1}$, S. Fountas ${ }^{3}$,

G.D. Nanos ${ }^{4}$ and T. Gemtos ${ }^{1}$

${ }^{1}$ University of Thessaly, Laboratory of Farm Mechanization, Fytoko Street, 38446, Volos, Greece

2 University of Georgia, Department of Crop and Soil Sciences, 2329 Rainwater Road, Tifton, Georgia, 31793, USA

${ }^{3}$ Agricultural University of Athens, Laboratory of Agricultural Engineering, Iera Odos 75, 11855, Athens, Greece

${ }^{4}$ University of Thessaly, Laboratory of Horticulture, Fytoko Street, 38446, Volos, Greece

*Corresponding author; E-mail: vliakos@uga.edu 